\title{
Tensiones en la transición. Prácticas sucesorias y autoridad cacical en Jesús de Machaca (Pacajes, Audiencia de Charcas, 1570-1690)
}

\author{
Tensions in the transition. \\ Succession practices and chiefly authority in Jesús de Machaca \\ (Pacajes, Audiencia de Charcas, 1570-1690) \\ Ariel J. Morrone \\ PROHAL, Instituto Ravignani, \\ Universidad de Buenos Aires-CONICET-Argentina \\ arielmorri@yahoo.com.ar
}

\section{Resumen}

En el mundo andino colonial, la muerte de un cacique constituía un acontecimiento clave en la vida política de los pueblos de reducción. Más allá del fin de la vida física, el paso de esas autoridades al plano ancestral abría coyunturas de transición caracterizadas por tensiones, pujas y reacomodamientos. Este artículo revisa los contextos de sucesión al cacicazgo del pueblo de Jesús de Machaca (corregimiento de Pacajes, Audiencia de Charcas) entre 1570 y 1690, para dar cuenta de los procesos de transición en el poder protagonizados por su renombrada (e historiográficamente recurrente) familia cacical, los Fernández Guarachi. Las sucesiones permiten estudiar los múltiples intereses políticos en pugna y ponderar las formas en que su rol mediador se ponía en juego entre el conjunto de habitantes del pueblo (organizados en ayllu) y las autoridades coloniales.

Palabras clave: Sucesión, Poder local.

\section{Abstract}

The death of a cacique (native lord) was a key event in the political life of pueblos de reducción (rural villages) in the colonial Andean world. Beyond the end of physical life, the passage of these authorities to the ancestral plane opened transition junctions characterized by tensions, bids and rearrangements. This article reviews the contexts of succession to the cacicazgo of Jesus de Machaca (corregimiento de Pacajes, Audiencia de Charcas) between 1570 and 1690 to account for the processes of transition in power carried out by its renowned (and historiog raphically recurrent) cacical family, the Fernández Guarachi. Successions allow us to study the multiple political interests in struggle and to assess the ways in which their mediating role was put into play between the set of villagers (organized in ayllu) and the colonial authorities.

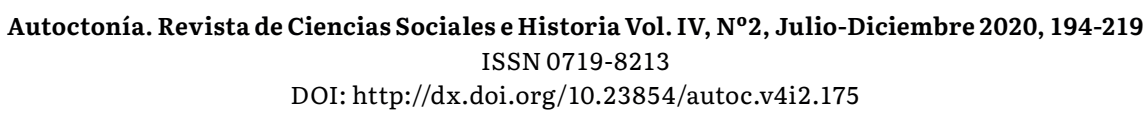


Keywords: Succession, Local power.

Recibido: 11 de octubre de 2020 - Aceptado: 27 de junio de 2020

"In memoriam Roberto Choque Canqui (1942-2020), maestro y guía en las sendas de la historia de Jesús de Machaca".

\section{Consideraciones iniciales}

El cuerpo del fallecido cacique yacía en su cama. A su alrededor, el cura doctrinero del pueblo, su viuda, hijos y demás deudos, y el conjunto de autoridades menores (principales ojilaqata) rezaban oraciones por la salvación de su alma (y/o por su llegada al alax pacha, mundo celestial en la cosmovisión aymara). Como dictaban la costumbre y la legislación, la muerte de un cacique principal de un pueblo de reducción del sur andino, durante los siglos de la temprana colonia, implicaba el inicio de un proceso sucesorio por el cual un miembro de la siguiente generación ocuparía el lugar del fallecido. La necesidad de garantizar la continuidad de un orden momentáneamente quebrado implicó, en no pocas oportunidades, la renegociación del entramado político local que involucraba a los miembros de la familia cacical, el conjunto de autoridades menores y los representantes del gobierno colonial, personificados en las figuras del corregidor de indios y el cura doctrinero.

En este trabajo analizamos las coyunturas sucesorias, los entramados del parentesco y la acción política de los caciques principales del pueblo de reducción de Jesús de Machaca, corregimiento de
Pacajes (actual provincia Ingavi del Departamento de La Paz, Estado Plurinacional de Bolivia) entre finales del siglo XVI y finales del siglo XVII. La sucesión al oficio cacical constituía un punto nodal en la redefinición de los criterios de legitimidad de las autoridades étnicas del sur andino, fundamentalmente a partir de la sistematización del dominio colonial operada durante el gobierno del virrey don Francisco de Toledo (1569-1581).

En efecto, el proceso de compactación de los repartimientos surandinos en torno a los pueblos de reducción fundados tras su visita general, la progresiva monetización de las cargas tributarias, la organización de los contingentes mitayos destinados al sostenimiento de la extracción minera de Potosí (verdadero "polo de crecimiento" de la economía colonial) y la consolidación de los diversificados mercados surandinos al calor de los "trajines", conformaron el contexto en el cual las autoridades étnicas debieron reeditar sus mediaciones económicas y sociopolíticas entre el sistema colonial y los ayllu que conformaban sus bases colectivas de apoyo (Spalding, 1974; Assadourian, 1982; Stern, 1986 [1982]; Glave, 1989; Pease, 1992; Choque Canqui, 1993; Platt et al., 2006; Mumford, 2012; Zuloaga Rada, 2012).

El pueblo de reducción de Jesús de Machaca formaba parte del corregimiento de Pacajes, jurisdicción rural dependiente de la ciudad de Nuestra Señora de La Paz (Mapa 1). Para 1573, contaba con un total 


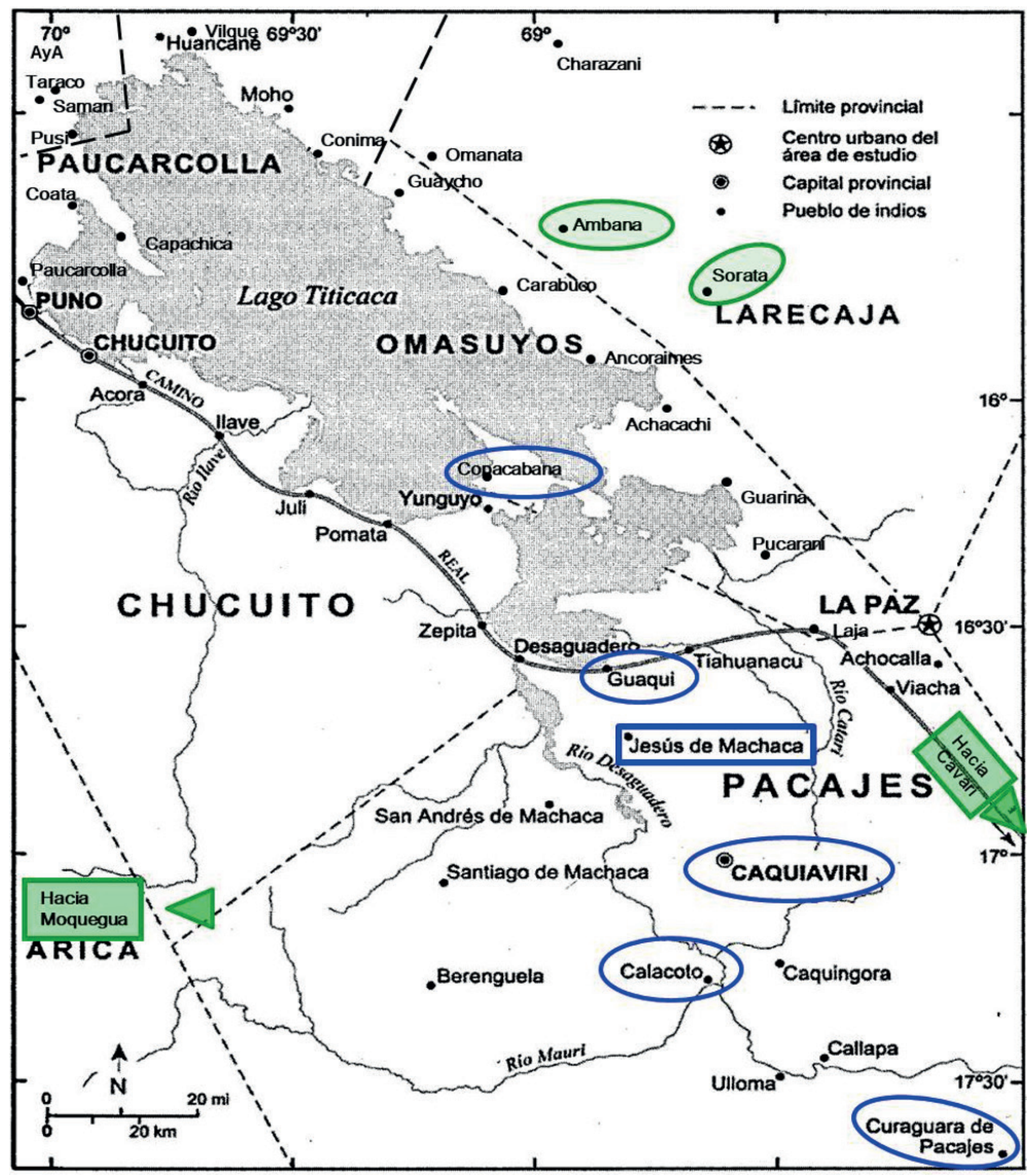

Mapa 1. El espacio lacustre y los pueblos del corregimiento de Pacajes mencionados en el texto. Elaboración del autor a partir de Thomson, 2006: 21. 
de 797 tributarios (4310 habitantes), sobre quienes se imputó una matrícula anual tasada en plata, piezas de ropa de abasca y ganado, que ascendía a 4978 pesos ensayados (Cook, 1975: 44-46)1․ La dotación productiva del pueblo (grandes rebaños de ganado, cultivos de altura) y el acceso a parcelas en los valles orientales en Larecaja y Cavari (maíz, trigo, coca) lo convirtieron en uno de los pueblos más ricos del corregimiento de Pacajes, y a sus caciques en importantes figuras políticas a escala regional.

La notoriedad de los caciques Fernández Guarachi se funda en cuatro décadas de investigación y producción historiográfica, cuyo punto de partida se ubica en la publicación de la transcripción paleográfica de gran parte del testamento de don Gabriel Fernández Guarachi, cacique de Jesús de Machaca entre 1620 y 1673 (Rivera Cusicanqui, 1978), y en posteriores trabajos de historiadores y antropólogos (Urioste de Aguirre, 1978; Gisbert, 1992; Choque Canqui, 1993, 1998b, 2003; Astvaldsson, 2000; Thomson, 2006; Morrone, 2013a). El exitoso desempeño de esta familia cacical en los diversificados mercados surandinos y en los estrados judiciales fue una piedra basal para la elaboración de un modelo de interpretación del rol de las autoridades nativas en el mundo andino colonial, como mediadores entre dos mundos (Stern, 1986 [1982]; Saignes, 1987a; Pease, 1992).

El testamento de don Gabriel Fernández Guarachi forma parte de un corpus documental más amplio resguardado en la Biblioteca Central de la Universidad Mayor de San Andrés(UMSA, La Paz), compuesto por nueve expedientes que incluyen probanzas de méritos y servicios, partidas de bautismo y matrimonio, provisiones dimanadas de la Audiencia de Charcas, traslados de Reales Cédulas, títulos y confirmaciones del oficio cacical, otros testamentos e informaciones de testigos. Se trata, en efecto, de insumos de gran valor historiográfico para la reconstrucción de la historia familiar y genealógica de los caciques Fernández Guarachi a lo largo de todo el período colonial. Orientados hacia un análisis sociopolítico del cacicazgo, abordamos este corpus documental de modo integral y en articulación con otras piezas dispersas en archivos bolivianos, argentinos y españoles para elaborar de una narrativa del poder étnico a escala local, a la luz de las críticas coyunturas sucesorias. Reconstruimos aquí varios episodios protagonizados por los miembros de la familia cacical y otros actores y actrices políticos, cuya trama puede seguirse a partir de los mapas y cuadros genealógicos adjuntos (Cuadro 1).

\section{Una sucesión “toledana” (1582-1583)}

Entre diciembre de 1582 y los primeros meses de 1583, don Fernando Axata Camaqui, cacique principal del pueblo de Jesús de Machaca, protocolizó tres testamentos ante Simón Titicuti, escribano del cabildo. A través de esos instrumentos, el cacique disponía la distribución de sus bienes materiales entre sus descendientes, el establecimiento de la sucesión al oficio cacical en favor de su primogénito legítimo, don Fernando Cayo Guarachi, y el balance de sus deudas y acreencias, junto con las acostumbradas indicaciones para el tratamiento de su cuerpo y su alma una vez acontecida su muerte (Abercrombie, 1998; Presta, 2002, 2009; Nowack, 2006; Ramos, 2010: 155-205; Burns, 2011; Noack y Nowack, 2017). 


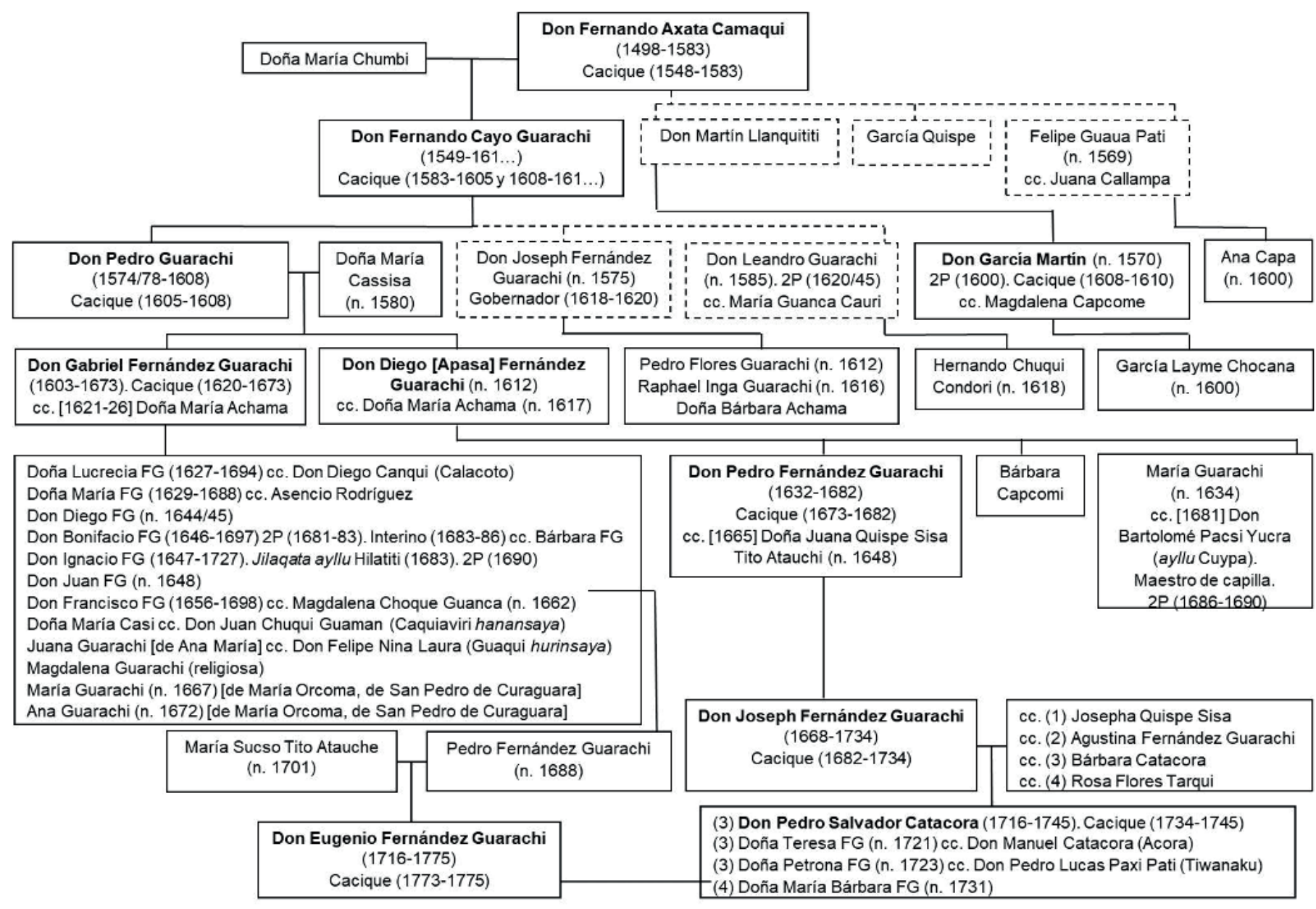

Cuadro 1. Genealogía de los caciques Fernández Guarachi de Jesús de Machaca. Elaboración del autor a partir de la documentación relevada en distintos archivos.

Estas piezas documentales forman parte de un expediente iniciado en junio de 1610 por don Fernando Cayo Guarachi, hijo y heredero de Axata Camaqui, contra su sobrino don García Martín (quien a la sazón también decía ser cacique del pueblo) por los derechos sobre unas casas y solar emplazados en las rancherías detrás de la iglesia de San Francisco de La Paz ${ }^{2}$. Incorporado como instrumento probatorio por don García Martín, el testamento de don Fernando Axata Camaqui constituyó una fuente nodal en la reconstrucción de la genealogía de los caciques de Jesús de
Machaca, en tanto don Fernando fue el ancestro apical o "genearca" del renombrado linaje cacical surandino, los Fernández Guarachi, que controló el gobierno efectivo del pueblo hasta mediados del siglo XVIII y de manera nominal hasta las primeras décadas del siglo XIX ${ }^{3}$.

En un trabajo anterior(Morrone, 2010a), reparamos en una serie de inconsistencias en la interpretación de este documento, entre ellas la "extendida minoridad" de don Fernando Axata Camaqui. Hasta entonces, la historiografía sostenía que, 
según su nieto don García Martín, el cacique había estado presente al momento de la fundación de La Paz en 1548, y que todavía era menor de edad para 1563, cuando solicitó al cabildo paceño el nombramiento de un curador ad litem para litigar contra los oficiales de la Real Hacienda por ciertas cargas de chuñu (Choque Canqui, 2003: 53-57).

Afortunadamente, el hallazgo de un documento de 1576 aportó datos hasta ahora inéditos con respecto a don Fernando Axata Camaqui. En el contexto de la recolección de un "donativo voluntario" entre los pueblos de reducción del corregimiento de Pacajes para solventar la guerra contra el imperio otomano, don Fernando Axata Camaqui fue convocado como testigo ${ }^{4}$. Decía entonces tener 78 años “poco más o menos”, lo cual arrojaría una fecha de nacimiento hacia 1498; lo que hace verosímil su presencia en la fundación de La Paz en 1548, cuando tenía 50 años 5 . En efecto, habría tenido 65 años para 1563, por lo que su condición de "menor" no remita a una cuestión etaria ("menor de edad) sino al status jurídico de minoridad, en tanto su capitis deminutio le impedía presentarse por sí mismo en los estrados judiciales (Clavero, 1994: 14-16).

En 1610, su nieto don García Martín alegaría que el capitán Alonso de Mendoza, fundador de La Paz, había concedido a Axata Camaqui un solar, que más tarde el beneficiado habría legado a su padre don Martín Llanquititi por cláusula testamentaria. Esta concesión no consta en el testamento (al menos no en los folios que perduraron); nada se menciona allí sobre Mendoza, con lo cual es plausible que la supuesta concesión fuera un argumento de don García Martín para desacreditar las aspiraciones de su contrincante ${ }^{6}$.

Habíamos señalado también la incertidumbre en torno a la presencia de don Fernando Axata Camaqui en 1608 en La Paz junto a su hijo don Martín Llanquititi, abasteciendo con mano de obra la construcción de diversos edificios de la ciudad (Choque Canqui, 2003: 57). ${ }^{7}$ El documento en cuestión señala que la presencia del cacique y su hijo en La Paz en 1548 "se ve por los autos de la adjudicacion y asignacion" de las casas próximas a San Francisco, que en 1608 realizara don Alonso de Tapia, teniente de corregidor de la ciudad, en favor de don García Martín; empero, la mención de la adjudicación no prueba la residencia de los aludidos en La Paz ${ }^{8}$.

Del mismo modo, tomamos distancia de nuestras propias afirmaciones (Morrone, 2010a: 221-222), toda vez que los nuevos datos sobrela edad de Axata Camaqui corroboran la extensión temporal de su gobierno (c.1548-1583). Ahora bien, la información empírica con que contamos no da cuenta de los orígenes de Axata Camaqui ni de su genealogía; ni siquiera su testamento, tipo documental donde usualmente el testador reconstruye su filiación, aporta datos en este sentido. Tampoco hallamos referencias al mítico Apu Warachi, supuesto líder regional preincaico, ni una memoria genealógica que pudiera extenderse hacia el "tiempo del Ynga" o al "tiempo inmemorial" (Urioste de Aguirre, 1978; Gisbert, 1980: 92-95). Este llamativo silencio convoca a reflexionar sobre los usos políticos de la memoria, sobre las interesadas pretensiones de legitimación de los caciques coloniales y sobre la formulación de relatos respecto de los 
míticos líderes preincaicos (Abercrombie 1998; Manríquez S. y Sánchez 2003; Jurado 2014). Por lo pronto, durante las últimas décadas del siglo XVI, los caciques de Jesús de Machaca se encontraban en plena resolución del "desafío toledano" de la mediación, debiendo articular prácticas de persuasión y negociación entre sus ayllu para enfrentar las cargas coloniales sin ver comprometida su legitimidad.

Suponemos que don Fernando Axata Camaqui murió a principios de 1583. En su testamento hay una referencia a los bienes repartidos entre sus hijos "el año pasado"; aunque el folio está roto, podemos deducir que se refiere al testamento de diciembre de 1582, pero el estado incompleto del expediente no permite conocer la fecha de elaboración de la pieza ulterior ${ }^{9}$. Con motivo de la apertura del testamento, registramos a quienes acompañaron a Axata Camaqui en sus últimos días: su segunda persona, don García Puchu Llanqui, dos alcaldes, un escribano y siete testigos, elegidos entre "los demas prinçipales de pachaca"10. La sucesión al oficio cacical recayó en su primogénito, don Fernando Cayo Guarachi, según cláusulas testamentarias que establecieron claramente los términos de la sucesión:

Yten declaro que tengo un hijo lixitimo llamado don Hernando Cayo lo qual an de ser por mi eredero y le dexo por caçique prinçipal de Machaca hanasaya.

Yten declaro que tengo tres hijos naturales a los quales mando que bivan bien y obedezcan al dicho don Hernando Caio el mayorasco y heredero'1.
Se trató, pues, de una sucesión “toledana”, de padre a hijo legítimo primogénito. Nada reclamarían para sí sus tres hijos naturales, don Martin Llanquititi, García Quispi y Felipe Guaua Pati² . La sucesión fue acompañada por el conjunto de autoridades menores del pueblo; incluso don García Puchu Llanqui, segunda persona del pueblo, quien en 1569 se había enemistado con el cacique principal Axata Camaqui, estaba presente al momento de la sucesión, sin interponer reclamo alguno13. Pero los conflictos en torno a la sucesión cacical no tardarían en arreciar.

\section{La inestabilidad sucesoria y surgimiento de un nuevo liderazgo (1605-1623)}

Don Fernando Cayo Guarachi ejerció el cacicazgo de Jesús de Machaca durante casi veinticinco años. El 21 de junio de 1605 hizo dejación del oficio en favor de su hijo mayor, don Pedro Guarachi, por encontrarse "viejo e impedido" para llevar adelante el gobierno efectivo del pueblo. Entre marzo y mayo de ese año, don Pedro había solicitado al corregidor de Pacajes, don Juan Calderón y Sotomayor, la asignación del oficio ante la avanzada edad de su padre, a quien le adjudicaba tener "más de 70 años". ${ }^{14}$ Su objetivo era cercenar los planes de su hermano don Joseph Guarachi, "hijo adulterino del dicho su padre, pretende suceder en el dicho govierno e casicasgo, con trazas, y mañas que ha tenido para servirle al presente por la vejez, e impedimiento del dicho don Fernando”. Ante la debilidad de su padre, su hijo y heredero, ya en edad de ejercer el oficio, buscó impedir que su “adulterino y mañoso" hermano se entrometiera en los asuntos del gobierno local. Don Pedro afirmó que reunía todas las condiciones: era hijo 
legítimo del cacique en funciones, "que por linea recta de varon sucede en el casicasgo", contaba con la habilidad, la suficiencia y la observancia de la religión cristiana requeridas, tenía más de 27 años y estaba casado con doña María Casi, con quien ya había tenido dos hijos: don Gabriel Guarachi y don Diego Apasa ${ }^{15}$.

Tras haber obtenido provisión favorable de la Audiencia de La Plata, don Pedro Guarachi la presentó ante el corregidor de Pacajes. En efecto, este accedió al oficio, pero su muerte a principios de noviembre de 1608, apenas tres años después, implicó que don Fernando Cayo Guarachi reasumiera el cacicazgo hasta (por lo menos) mediados de 1610, fecha en que estallaría el pleito con su sobrino, don García Martín, por la propiedad de las casas y solares en La Paz.

A la muerte de don Pedro Guarachi en 1608, el cacicazgo debería haber pasado a su hijo mayor don Gabriel Guarachi, quien a la sazón tenía cinco años; empero, su corta edad explica que su abuelo, don Fernando Cayo Guarachi, se hiciera cargo del gobierno del pueblo. Esta segunda etapa se caracterizó por una fuerte rivalidad con su sobrino, don García Martín. Entre 1608 y 1610, don García Martín ostentó los oficios de cacique principal de Jesús de Machaca y alcalde mayor de naturales de La Paz, en cuya virtud recibió, en enero de 1609, un poder de su encomendero, don Diego Dávalos y Figueroa, para solicitar a los caciques del pueblo los tributos adeudados y tomar las cuentas correspondientes al corregidor ${ }^{16}$. Sin embargo, momentáneamente, el poder otorgado por el encomendero posicionaba a don
García Martín en un rol de autoridad superior con respecto a los otros caciques del pueblo.

Cabe destacar que, en la carta de poder, el cacique era llamado “don García Martínez”, en un claro intento por "patronimizar" su apellido, derivando del nombre de su padre (don Martín) un apellido hispánico ("Martínez", en tanto "hijo de Martín"). Entendemos que este acercamiento de don García Martín[ez] a las pautas onomásticas, filiatorias y culturales hispánicas, era correlativo al apoyo de miembros notables del segmento dominante de la sociedad paceña (posesión de las casas de parte del teniente de corregidor de La Paz en 1608, apoderado de su encomendero para la cobranza del tributo en 1609). ¿Acaso ante la avanzada edad de don Fernando Cayo Guarachi, las autoridades hispánicas preferían entablar vínculos con su sobrino, un cacique más joven devenido nuevo interlocutor válido?

La inesperada muerte de don Pedro Guarachi en 1608 y la avanzada edad de su padre habilitaron un margen para las pretensiones de don García Martín[ez], un candidato "segundón" del linaje cacical, quien se fortaleció en la coyuntura de 1608-1610 a partir del ejercicio del oficio de alcalde mayor de naturales. Pero cabe, asimismo, una segunda lectura: una vez muerto el cacique, don García Martín[ez] era el varón de mayor edad de su generación. ¿Estaría amparando sus pretensiones en una pauta de sucesión adélfica, es decir, "entre hermanos" (Remy Simatovic, 2010: 39-47; Morrone, 2015; Arnold, 2018: 164-172)? Por el momento, no contamos con información para responder este interrogante. Para diciembre de 1618, don Joseph Fernández Guarachi (hermano 
de don Pedro Guarachi, tildado por éste de "adulterino y mañoso") ejercía el cacicazgo, debiendo responder ante las levas de mitayos para las minas de Oruro, bajo el liderazgo regional de don Gabriel Cusi Quispe, cacique principal de Caquiaviri17. Advertimos que don Joseph también había combinado el patronímico "Fernández" (en tanto "hijo de Fernando") con su "apellido nativo" Guarachi. ¿Se proponía emular a su primo don García Martín[ez] para acceder así al favor de las autoridades coloniales hacia la "rama mayor" de este linaje en formación?

Descalificado por su hermano mayor don Pedro, don Joseph fue el primer cacique de Jesús de Machaca que ostentó el apellido Fernández Guarachi, en lo que entendemos constituyó una estrategia simultánea de posicionamiento político, castellanización onomástica, emulación de elite, hibridación cultural y manipulación de la sucesión. Desde (por lo menos) 1618, la portación del apellido Fernández Guarachi sería sinónimo de poder efectivo y doble legitimidad, en tanto el primer componente daba cuenta de la adopción del sistema onomástico hispánico mientras que el segundo, heredado de su padre, condensa la memoria genealógica de su familia en términos nativos. Durante la siguiente generación, el apellido se consolidaría como metonimia del poder cacical, del gobierno efectivo del pueblo, del entramado de sus redes mercantiles, del patrimonio consolidado y de la relevancia política del linaje a escala regional.

El acceso al oficio cacical de don Gabriel Guarachi, hijo y heredero de don Pedro (y sobrino de don Joseph), tuvo lugar en un contexto local cruzado por una doble crisis. Por un lado, una crisis sucesoria inaugurada por la inesperada muerte de su padre en 1608 y la disputa entre otros miembros del linaje durante la década de 1610. Por el otro, una crisis de reproducción social de los ayllu del pueblo, originada en el progresivo despoblamiento que respondía al efecto combinado del "ausentismo táctico anti-fiscal", el inicio de un levantamiento de la población que habitaba en las riberas del río Desaguadero, y los estragos demográficos causados por una serie de epidemias y malas cosechas (Saignes, 1987b; Wachtel, 2001: 362-363).

En este contexto, el corregidor de Pacajes, don Juan Cegarra de las Roelas, emprendió el 14 de febrero de 1620 una revisita ordenada por el virrey don Francisco de Borja y Aragón, príncipe de Esquilache. Al día siguiente, el corregidor registró en el padrón del ayllu Hilatiti que don Gabriel Guarachi, de 17 años, era el cacique principal, mientras que su tío don Joseph Fernández Guarachi, de 45 años, gobernaba el repartimiento en su nombre ${ }^{18}$. Mientras se desarrollaba la revisita, don Gabriel solicitó al corregidor el otorgamiento de la posesión del cacicazgo como hijo y nieto de los anteriores caciques.

El 25 de febrero, la ceremonia de posesión de don Gabriel Guarachi como cacique de Jesús de Machaca siguió los pasos acostumbrados. En primer lugar, el corregidor recibió la información del padre Gómez de Rivera, cura del pueblo, y de los principales de cada ayllu, corroborando la filiación de don Gabriel, sus derechos sobre el cacicazgo "y que es habil, y suficiente para quando tenga edad legitima, governar el dicho casicasgo". Acto seguido, ordenó traer una tiana sobre la que sentó a don Gabriel para que éste recibiera el 
reconocimiento de su tío, el gobernador don Joseph Fernández Guarachi, y del resto de los principales del pueblo, quienes lo abrazaron en señal de reconocimiento siguiendo el orden de preeminencia jerárquica de cada ayllu ${ }^{19}$. Finalmente, y dado que don Gabriel no contaba aún con la edad suficiente para ejercer el gobierno, el corregidor ordenó “que en el ynterin que el dicho don Gabriel Guarache es de edad legitima para usar el dicho casicasgo, se le acuda con la mitad del salario, y mitad de chacaras y mitad de servicio, que el capitulo de tasacion manda de le dé al casique principal" 20 .

Sería recién en enero 1623 cuando don Gabriel Guarachi, el cacique de Jesús de Machaca, aparezca en la documentación como don Gabriel Fernández Guarachi, en una certificación sobre los resultados de la visita ordinaria realizada en diciembre del año anterior por el corregidor don Diego Bravo de Saravia ${ }^{21}$. Ejerciendo plenamente el cacicazgo a sus 20 años, con pleno apoyo de su núcleo familiar más cercano y sin rivales que pudieran disputar su liderazgo, don Gabriel portaba la versión completa del apellido familiar, verdadero símbolo del poder político en términos andino-coloniales en tanto representación de su condición de mediador "entre dos mundos" (Saignes, 1987a).

Entre 1605 y 1620 asistimos, pues, a situaciones sucesorias de distinta resolución. La primera ocurrió cuando don Fernando Cayo Guarachi hizo dejación del oficio en favor de su hijo don Pedro Guarachi, para reasumirlo tras la inesperada muerte del joven cacique. El hiato documental entre 1610 y 1618 nos impide conocer la fecha del fallecimiento de don Fernando, pero tanto su sobrino don García Martín[ez] como su hijo natural don Joseph Fernández Guarachi ejercieron funciones de liderazgo durante la minoría de edad del "legítimo heredero", don Gabriel Guarachi. Finalmente, en el marco de la revisita de 1620, don Gabriel solicitó la posesión del oficio, acompañado por su tío y el resto de las autoridades del pueblo. Despejado el panorama sucesorio, a partir de la década de 1620 don Gabriel Fernández Guarachi comenzaría a tramar una serie de redes personales, familiares, clientelares y de negocios que lo transformaron en uno de los más influyentes caciques del sur andino colonial, lo cual se traducirá en una voluminosa producción documentaly, en efecto, en una notoria centralidad historiográfica.

\section{El legado del cacique y la sucesión colateral (1673)}

Nuestra investigación realiza aquí un salto medio siglo, durante el cual asistimos al estallido de los procesos migratorios, la "disipación” de los pueblos de reducción altiplánicos, el enrarecimiento del panorama socioétnico del sur andino a partir del fenómeno del "forasterismo", y la progresiva apropiación hispanocriolla de los recursos nativos (tierra, ganado, mano de obra) en los valles orientales (en no pocas oportunidades, vinculadas a las visitas y composiciones de tierras), lo que a su vez generó presiones por parte de los dueños de minas frente al gobierno colonial para el cumplimiento de una mita toledana que, a la sazón, se hallaba altamente distorsionada (Saignes, 1984, 1985, 1987b).

A principios de 1673, un ya viejo don Gabriel Fernández Guarachi notaba palmariamente que el final de sus días se encontraba próximo. Más 
de medio siglo al frente del gobierno del pueblo le había granjeado grandes riquezas e importantes cuotas de capital social, todo lo cual quedó reflejado tanto en su testamento, otorgado en Potosí el 10 de marzo, como en un codicilo firmado el 13 de junio en su pueblo. En esta oportunidad, volveremos sobre el testamento del cacique para reconstruir el panorama genealógico de su descendencia y el decurso que tomó la sucesión al oficio cacical.

Durante la primera mitad de la década de 1620, don Gabriel Fernández Guarachi había contraído matrimonio con doña María Hachama, hija de don Francisco Achu Yucra, jilaqata del ayllu Calla del mismo pueblo, y de Lucrecia Titi. Este matrimonio ilustraba una clara intención por parte del entonces nuevo cacique (y del resto de los principales del ayllu Hilatiti, al que pertenecía) por obtener apoyos políticos internos ${ }^{22}$. La consolidación de un frente interno y el entramado de redes sobre las que luego el cacique emprendería sus negocios en torno a la comercialización de textiles fueron factores claves para la concreción de este enlace. Según consta en el testamento,

durante el dicho matrimonio que fueron seis años tubimos algunos hijos y solo quedaron vivos doña Lucrecia y doña Maria Fernandez Guarache declarolas por tales mis hijas legitimas. (...) Iten declaro, que despues que enviudé e tenido cinco hijos varones naturales y quatro mugeres que son $=$ Don Diego $=$ Don Bonifacio $=$ Juan $=$ Ignacio $=$ Francisco Guarache $=$ Doña Maria Casi $=$ Magdalena Guarache $=$ Juana Guarache $=\mathrm{Y}$ otros dos hijos de Maria Orcoma = Declarolos por mis hijos naturales ${ }^{23}$.
Aprovechamos este testimonio para echar luz sobre el conjunto de prácticas matrimoniales diseñadas por el cacique para su descendencia. Particularmente, aludimos a una serie de datos genealógicos, hasta ahora no observados en conjunto, que complejizan en panorama político local e iluminan las cuidadas estrategias cacicales de reproducción social, material y simbólica. Comenzaremos por señalar que don Gabriel Fernández Guarachi habíaimpulsado el matrimonio de tres de sus hijas con caciques del corregimiento de Pacajes. Su hija legítima mayor, doña Lucrecia Fernández Guarachi, estuvo casada con don Diego Canqui, cacique de Calacoto. Nacido hacia 1620, don Diego ya ejercía el gobierno del pueblo en 1645 "en lugar de su padre", don Diego Apasa. ${ }^{24}$ El yerno de don Gabriel Fernández Guarachi fue uno de los caciques más perjudicados por el despoblamiento de los pueblos atiplánicos y la consecuente crisis de la mita potosina, habiendo ejercido como capitán de mita en 1646 y $1661^{25}$.

Por otro lado, una de sus hijas naturales, doña María Casi, había casado en 1656 con don Juan Choque Guaman, cacique de Caquiaviri, según consta en el testamento de éste. A través del enlace, don Gabriel Fernández Guarachi entabló un vínculo personal con Choque Guaman, rico cacique propietario de ganado y de tierras en términos de San Juan de Cavari (corregimiento de Sica Sica), comerciante de vino de Moquegua y poseedor de una cultura material altamente hispanizada (vestimenta, bienes del hogar) (Choque Canqui, 1998a: 20-21). Finalmente, otra de sus hijas naturales, Juana Guarachi, fue esposa de don Felipe Nina Laura, cacique principal de Guaqui hurinsaya, quien en 1657 representó a su suegro 
en la certificación de los títulos de una estancia ubicada en términos del pueblo de Santiago de Ambaná, corregimiento de Larecaja ${ }^{26}$.

En efecto, los matrimonios de tres de sus hijas vincularon políticamente a don Gabriel Fernández Guarachi, el potentado cacique de Jesús de Machaca, con sus pares de Calacoto, Guaqui y Caquiaviri. Esto le permitió fortalecer su posición de liderazgo en el corregimiento de Pacajes, retroalimentado por su acceso al cargo de capitán de mita, por los negocios desplegados en el "espacio del trajín" y por su función como "escudo protector" del resto de los caciques de la región ante las justicias coloniales (Morrone, 2014). A tal punto eran políticamente atractivas las hijas de don Gabriel Fernández Guarachi que Pedro Carrillo, apoderado del gremio de azogueros de Potosí en el pleito contra el cacique por la vigencia del cargo de capitán de mita, sugirió en abril de 1662 que un corregidor de Pacajes había pretendido casarse con una de ellas ${ }^{27}$.

Su temprana viudez no llevó a don Gabriel a un nuevo matrimonio. Si bien desconocemos los nombres de los hijos legítimos que murieron vita patris, el nacimiento en 1632 de su sobrino don Pedro, hijo de su hermano menor don Diego, aseguró la línea sucesoria según los criterios hispánicos de legitimidad, varonía y primogenitura. Así como su tío don Joseph había ejercido el gobierno durante su minoridad, y sumido en una grave enfermedad, en 1660 don Gabriel asoció a su sobrino don Pedro a las tareas de gobierno. En efecto, don Pedro se encargó del pago de los tributos y ejerció el oficio de capitán de mita en 1660,1664 y $1668^{28}$.
En su testamento de marzo de 1673, don Gabriel legó a don Pedro 20.000 pesos para la compra de cuatro chacras, de cuyos procedidos debían adquirirse los materiales e instrumentos necesarios para la edificación y ornamentación de una nueva iglesia para el pueblo de Jesús de Machaca. También declaró que don Pedro le debía alrededor de 7500 por la mitad de los gastos incurridos en un pleito por una tierras cuya propiedad compartían en términos del pueblo de La Magdalena de Sorata (corregimiento de Larecaja); otros 2650 pesos por una libranza y cesión otorgada a don Pedro por el maestre de campo don Joseph de Torres y Zúñiga, anterior corregidor de Pacajes; y otros 1650 pesos por la venta de unas botijas de vino en Potosí29. Don Pedro debía pagar el total de la deuda (que ascendía a 11.800 pesos) a los hijos y herederos del cacique, es decir, sus primos, entre quienes don Gabriel había distribuido sus bienes y sus propiedades inmuebles ${ }^{30}$.

Don Pedro accedió plenamente al cacicazgo a mediados 1673, sucediendo a su tío aunque en una situación de desventaja material con respecto al resto de los miembros del linaje, en virtud de las deudas acumuladas. Empero, contaba con recursos de otra índole para contrabalancear tal inconveniente. Hacia 1665, había contraído matrimonio con doña Juana Quispe Sisa Tito Atauchi, hija de don Juan Mayta Capac Tito Atauchi, cacique del pueblo de Nuestra Señora de Copacabana. Este enlace representaba un punto clave de acumulación de capital simbólico para el linaje Fernández Guarachi, toda vez que la familia cacical de Copacabana descendía de la panaqa del Inka Viracocha (del Río, 2009; Morrone, 2018). Entre otros bienes, doña Juana llevó en dote los 
derechos de posesión sobre las islas de Titicaca, Coyabaya y Coati (actuales islas del Sol y de la Luna), por un total de 5000 pesos $^{31}$. Junto con la península de Copacabana, estas islas formaban parte de la geografía sagrada andina desde tiempos preincaicos, resignificada en torno al culto solar por el Tawantinsuyu y por el culto mariano a partir de la instalación de la milagrosa imagen de Nuestra Señora de la Candelaria (Ramos Gavilán, 2015 [1621]; Salles-Reese, 1997; Bauer y Stanish, 2001; Costilla, 2005; Morrone, 2019). Si bien el matrimonio de don Pedro Fernández Guarachi con una mujer del linaje cacical de Copacabana se inscribió en la misma línea de los enlaces de sus primas (las hijas de don Gabriel) con otros caciques del lago, al mismo tiempo constituyó un acontecimiento inédito, toda vez que hasta entonces los hijos y herederos de los caciques de Jesús de Machaca habían casado con mujeres del propio pueblo, con el objetivo de consolidar un frente interno de alianzas que fortalecieran su posición política. La incorporación por vía matrimonial de una mujer foránea, ajena al núcleo de influencia local, ampliaba las redes relacionales de los Fernández Guarachi e incrementaba sus capitales económico, social y simbólico, toda vez que doña Juana acreditaba una ancestralidad y patrimonio altamente consolidados.

En 1668, don Pedro Fernández Guarachi combatió a favor de la causa real durante las secuelas de la rebelión de Laicacota en La Paz y en los valles occidentales de Moquegua, y en 1676 participó de las campañas punitivas sobre la población lacustre junto al corregidor de Pacajes y al gobernador de Chucuito. Asimismo, en 1678 fue nombrado capitán general del corregimiento de
Pacajes para la defensa del puerto de San Marcos de Arica durante la amenaza inglesa ${ }^{32}$. Durante su cacicazgo operó como comerciante de vino y coca en el mercado potosino, sobre la base de las operaciones previas de su tío don Gabriel (Choque Canqui, 2003: 103-106). Esta combinación de tipos y dotaciones de capital reforzó el prestigio, la influencia y el peso específico que la familia Fernández Guarachi venía construyendo desde fines del siglo XVI, los cuales trascendieron la inesperada muerte de don Pedro, acaecida entre julio y diciembre de 1682, para incrementarse más aún durante el gobierno de su hijo y heredero, don Joseph Fernández Guarachi33. Empero, su sucesión no trascurriría por senderos apacibles.

\section{Los arreglos parentales (1682-1686)}

A pesar de lo señalado en torno al posicionamiento político de don Pedro Fernández Guarachi, su fallecimiento en 1682 abrió dos frentes de conflictividad: el gobierno efectivo del pueblo y la cancelación de nuevas deudas; ambos debieron ser resueltos por sus familiares más cercanos.

El primer problema radicaba en que su hijo y heredero, don Joseph Fernández Guarachi, no contaba con la edad suficiente para asumir el oficio. Nacido el 17 de marzo de 1668, al momento de la muerte de su padre contaba con apenas 14 años ${ }^{34}$. Había aprendido sus primeras letras de la mano del teniente de cura del pueblo por decisión de su padre, continuando sus estudios de gramática en el colegio jesuita de La Pazy, posteriormente, en el de San Bernardo del Cuzco, donde entró en contacto con el universo cultural de la antigua capital incaica ${ }^{35}$. 
La formación cuzqueña de don Joseph se vio interrumpida por la muerte de su padre y por la férrea intervención de don Juan Francisco de Inda Vidaurre, corregidor de Pacajes, quien ordenó sostener al joven e inexperto cacique al frente del gobierno del pueblo. Esto llevó a que doña Juana Quispe Sisa, como tutora y curadora de su hijo, denunciara esta perturbadora conducta del corregidor ante el virrey duque de La Palata, de quien obtuvo en marzo de 1683 una provisión que ordenaba al corregidor la designación de un cacique interino, a partir de una terna, hasta tanto don Joseph llegara a la edad suficiente. ${ }^{36}$.

El segundo conflicto asociado a la sucesión de don Pedro Fernández Guarachi radicaba en una gravosa deuda pendiente. El corregidor Inda Vidaurre había encargado al cacique el trajín de cierta cantidad de botijas de vino de Moquegua por 12.000 pesos; de manera inesperada, don Pedro fallecería durante el expendio del negocio, "para cuya cobranza le vendieron todos sus bienes y hacienda, de suerte que ha quedado su mujer e hijos destruidos y sin tener un pan que comer" 37 .

No serían éstos los únicos menesteres que debió atender la viuda del cacique. En diciembre de 1684, doña Juana presentó la provisión virreinal de marzo de 1683 ante el nuevo corregidor, el general don Diego Barraza Enríquez, quien de inmediato designó como cacique interino a don Bonifacio Fernández Guarachi, tío segundo de don Joseph, quien venía ejerciendo el oficio de segunda persona desde (por lo menos) $1681^{38}$. De este modo, el gobierno quedaba interinamente en manos de uno de los hijos naturales de don Gabriel Fernández Guarachi. Este vínculo había sido reforzado por el matrimonio de don Bonifacio con doña Bárbara Fernández Guarachi, otra de las hijas naturales de don Pedro y, por lo tanto, media hermana de don Joseph. Así pues, entre el joven cacique y el interino se tramaba un parentesco doble: su tío segundo era, además, su cuñado. La integración de miembros "ilegítimos" del linaje a la rama "legítima" a cargo del cacicazgo garantizaba tanto la transición sucesoria como el desdibujamiento de la ilegitimidad (Morrone, 2018: 22-24).

En efecto, a la muerte de don Pedro se planteó una distribución de funciones entre los miembros del linaje. Mientras la viuda doña Juana Quispe Sisa, como madre, tutora y curadora de don Joseph, enfrentó en los estrados judiciales las presiones del corregidor y ajustó sus deudas, don Bonifacio Fernández Guarachi, segunda persona, se hizo cargo del gobierno interino del pueblo. Esta situación cambió en julio de 1686, cuando don Joseph, ya con 18 años, obtuvo del corregidor Barrasa la designación como cacique principal y gobernador ${ }^{39}$. Cabe destacar aquí, una vez más, la acción mancomunada de las dos "ramas" del mismo linaje: la "rama legítima", a través de la cual el oficio cacical se heredaba de padres a hijos, y la "rama natural", representada por la descendencia masculina de don Gabriel Fernández Guarachi, con cuyos miembros se articulaban negocios, matrimonios y alianzas políticas. Ambas ramas se reencadenaban, pues, tanto para cerrar el conflicto político interno como para licuar las máculas de ilegitimidad que pendían sobre los descendientes "naturales" de don Gabriel. De este modo, la preferencia por un matrimonio hacia el interior de la parentela cercana consolidaba las relaciones entre colaterales y garantizaba la 
protección y reproducción del patrimonio material e inmaterial del linaje (Bestard, 1998: 128-168).

\section{Consideraciones finales: el arte de navegar la transición}

Este trabajo buscó recrear las coyunturas específicas de la sucesión al oficio cacical en el pueblo de Jesús de Machaca para ponderar, entre otras aristas, el modo específico en que su familia cacical devino en uno de los principales linajes del sur andino colonial entre finales del siglo XVI y finales del siglo XVII. En tanto situaciones de transición múltiple (entre la vida y la muerte, entre el fin de un cacicazgo y el inicio de otro), las sucesiones permiten analizar el conjunto de interacciones políticas tramadas tanto en el pueblo como en el corregimiento de Pacajes (como la vinculación con otras familias cacicales) y a escala regional. En efecto, el entramado de redes sociales, parentales, políticas y económicas se extendía desde Jesús de Machaca hasta La Paz (ciudad cabecera de la jurisdicción), el Cuzco (entorno cultural privilegiado y espacio simbólico de la memoria incaica), los valles orientales de Larecaja y los occidentales de Moquegua (zonas de producción de bienes trajinados por encargo de los caciques), Copacabana (residencia de una familia cacical de ascendencia incaica) y Potosí (eje de la economía colonial y residencia de los capitanes de mita, responsables del abastecimiento de mano de obra forzada).

A la hora de comparar las instancias sucesorias, podemos distinguir las ocurridas durante situaciones de enfermedad prolongada del cacique, que generalmente incluían la protocolización de una pieza testamental (don Fernando Axata Camaqui en 1582-1583, don Gabriel Fernández Guarachi en 1673), de las muertes repentinas que (como en el caso de don Pedro Guarachi en 1608) dieron lugar a sucesiones ab intestato, aunque guardando las normas establecidas. La elaboración de un testamento habilitaba márgenes de maniobra y negociación entre el testador, su entorno familiar y su núcleo cercano, que no podían tramarse cuando el cacique fallecía inesperadamente. Más allá del reparto efectivo de los bienes materiales, muchos eran los puntos a esclarecer en torno a la "herencia inmaterial", constituida por la sucesión en el oficio cacical, entendido en términos cercanos al mayorazgo hispánico, y por dotaciones inconmensurables de capital social y simbólico; de allí la variedad de acreencias y tareas en juego durante la coyuntura sucesoria.

Durante su vida, cada cacique creó, renovó y articuló una serie de redes relacionales que se extendían tanto a los miembros de los ayllu, sus autoridades y demás habitantes de su pueblo como con los distintos engranajes del poder colonial a escala local y regional (específicamente, con los curas doctrineros y con los corregidores de indios) para construir acuerdos mínimos de gobierno. Estas redes del poder negociado debieron reacomodarse una vez ocurrido el deceso del líder étnico; de ahí la trascendencia de pautar una sucesión, tanto por arreglos de palabra como por piezas testamentarias cuidadosamente labradas. Si el cacique llegaba a una edad avanzada y/o se hallaba gravemente enfermo, al punto de no poder ejercer su oficio, la incorporación de miembros varones de la generación siguiente (hijos, sobrinos, incluso yernos) constituía un 


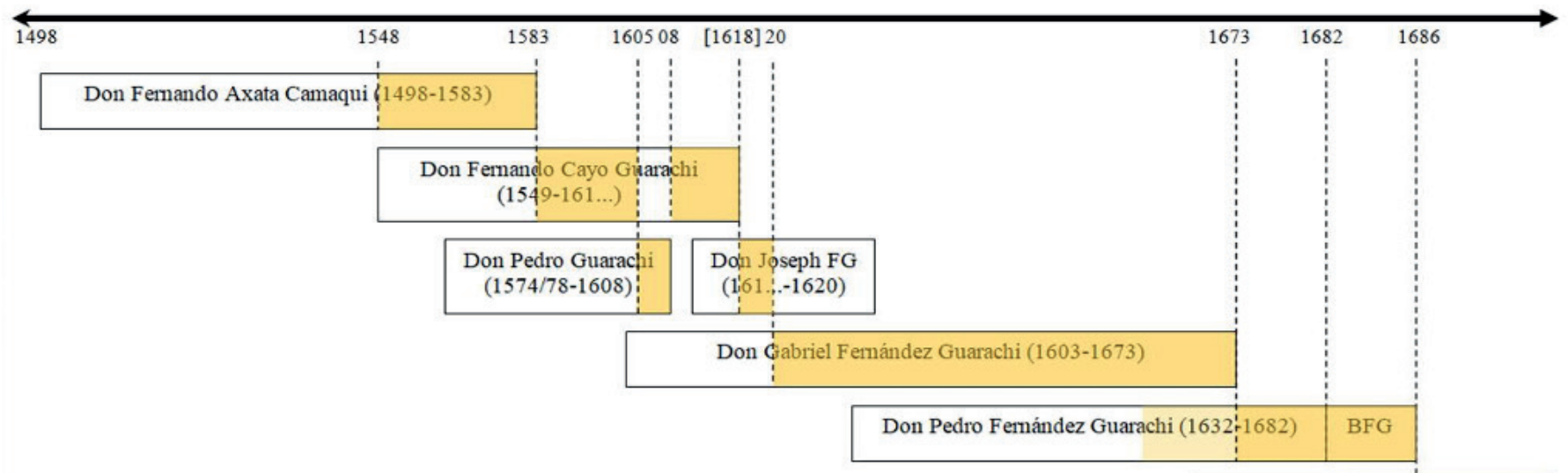

Cuadro 2. Sucesión al cacicazgo en Jesús de Machaca. Elaboración del autor.

salvoconducto para sortear el inicio del período transicional (de la Puente Luna, 2016: 68-69). Esta asociación generaba instancias de aprendizaje y entrenamiento en las prácticas del gobierno cacical (como la elaboración del testamento) que quedaban coartadas ante la imprevista muerte del cacique en ejercicio (Cuadro 2). En cualquier caso, una vez fallecido el cacique, la transición continuaba durante los primeros tiempos de gobierno del sucesor hasta que éste, en virtud de su capacidad para maniobrar la situación política local, lograra reconfirmar indiscutidamente su liderazgo ${ }^{40}$.

En esta línea de interpretación, la sucesión cacical constituía uno de los elementos clave en el arte de navegar la transición. Desde la perspectiva de las altas esferas de la administración colonial, se trataba de un reemplazo en el oficio. Ahora bien, si corremos el foco hacia la perspectiva nativa, la sucesión importaba otras consideraciones. La muerte del cacique y el inicio del ciclo sucesorio abrían una brecha en la reproducción de sus funciones mediadoras, las cuales garantizaban la continuidad misma del orden social. En tanto uno de los atributos de la autoridad nativa era el sostenimiento del orden espacio-temporal y simbólico, la ancianidad del cacique y su consecuente fallecimiento abría un inestable período de liminalidad que amenazaba las condiciones de reproducción social del colectivo a su cargo y que, por tanto, debía ser conjurada a través la acción ritual mancomunada del resto de las autoridades del pueblo (Martínez Cereceda, 1995; Ramírez, 2005: 161-179). La escena protagonizada en 1620 por don Gabriel [Fernández] Guarachi, sentado en la tiana para recibir el abrazo de los principales del pueblo, resulta representativa de este mecanismo colectivo de "transición ordenada" en el contexto de la sucesión al oficio cacical. Exceptuando la "crisis sucesoria" y el "hiato documental" de 1608-1618, la presencia de las autoridades menores en cada coyuntura transicional, manifestando su apoyo al nuevo cacique, constituye uno de los principales rasgos de firmeza del tipo de liderazgo construido por los caciques Fernández Guarachi, incluso cuando las 
sucesiones transcurrieron en contextos de caída demográfica o con deudas por saldar.

El reordenamiento toledano había limitado el acceso al oficio cacical a unas pocas familias en cada pueblo de reducción, cristalizando la pauta sucesoria en términos de primogenitura, legitimidad y mayorazgo. No sin conflictos, esta pauta fue incorporada por las elites nativas, aunque la capacidad de mantener el oficio dentro de la misma familia varió considerablemente en función de un conjunto de factores que intervinieron en la reproducción del capital político de cada cacique principal: el caudal demográfico, la dotación de recursos productivos y su rendimiento, el acceso a nichos ecológicos complementarios, el impacto de las cargas tributarias, los márgenes de negociación con las autoridades hispánicas y con las autoridades menores del pueblo, el desempeño en las plazas mercantiles y en los estrados judiciales, la capacidad administrativa para convocar al entero de la mita, entre otros. Para mediados del siglo XVII, verificamos un patrón de articulación sociopolítica a escala regional, que implicó un proceso simultáneo de encumbramiento de unos pocos caciques poderosos y de abroquelamiento de gran cantidad de caciques de menor porte, escudados detrás de los primeros en torno a redes de tipo clientelar (Morrone, 2014, 2015, 2016).

Este esquema de situación tuvo su correlato en materia sucesoria. Contingencias como la inexistencia de un heredero "legítimo" (status caro al sistema jurídico hispánico, que no a los fines prácticos de la reproducción del linaje) y/o "hábil y suficiente" (en términos andino-coloniales), la presencia de líneas colaterales o candidatos rivales cuyas pretensiones al oficio cuestionaran la legitimidad del sucesor, la manifiesta enemistad de un corregidor o de un cura doctrinero (o de ambos) que alteraran la sucesión cacical con la intrusión de figuras acólitas ajenas al entramado político local, por mencionar sólo algunas, constituyen verdaderas líneas de tensión que se reeditaban tras la muerte de cada cacique. En efecto, la sucesión resulta un instrumento analítico clave para ponderar la firmeza o debilidad del liderazgo nativo.

El estudio pormenorizado de las sucesiones cacicales en Jesús de Machaca nos permitió, asimismo, dar con el contexto específico en que se labró el apellido Fernández Guarachi, constituido por el solapamiento de elementos hispánicos y andinos, resultando en una unidad de significación donde se articularon y consustanciaron el poder, el parentesco, la patrimonialización de un oficio heredable, el linaje, la territorialidad y la memoria ${ }^{41}$. La retroalimentación de los distintos componentes de capital acumulado se tradujo, en efecto, en la proyección de ese apellido a través de las generaciones como una marca de status ostentado ante los distintos segmentos de la sociedad colonial, y como una referencia política clave en un contexto regional donde la práctica de transmisión onomástica era variable y donde pocas familias cacicales lograron constituir un linaje con apellido transmisible en términos de "herencia inmaterial" y patrimonializar corporativamente el oficio (Levi, 1990; Boixadós, 1997, 2008; Sanabria, 2001; Medinacelli, 2003: 231-239; Thomson, 2006: 90-92; Herzog, 2007; Morrone, 2015). 
Más aún: en el caso de don Gabriel Fernández Guarachi quizás operó otro componente. Es probable que, al momento de su bautismo en noviembre de 1603, sus padres hayan elegido imponer al recién nacido el nombre del encumbrado e influyente cacique del momento, don Gabriel Cusi Quispe de Caquiaviri, como mecanismo de transferencia del capital simbólico asociado a ese nombre (Bourdieu, 1991: 245-246; Presta, 2000: 196-197; Ramírez, 2006). Tal acto ritual habría implicado el establecimiento de una conexión que acaso actualizara lazos de alianza sociopolítica preexistentes, y que se reconfirmarían medio siglo después por el matrimonio de la hija del cacique de Jesús de Machaca con el cacique de Caquiaviri, tal como vimos. Nuevamente, nos encontramos ante una condensación simbólica en el nombre de pila, que remite a una figura de altísima centralidad en el tradición judeocristiana, en tanto el Arcángel Gabriel encarna la "fortaleza de Dios" (tal su traducción del hebreo) como mensajero de la Anunciación. La imposición de este nombre revela, asimismo, la implicación de la familia cacical de Jesús de Machaca en la observancia de los preceptos cristianos, atributo clave para obtener el beneplácito de las autoridades coloniales, en tanto se esperaba de las elites nativas fungieran de ejemplo para la cristianización del conjunto de la población.

El estudio de las coyunturas sucesorias nos permitió atender al conjunto de prácticas que posibilitaron la consolidación de la familia cacical en el gobierno del pueblo y la forja de un apellido que identificaría al linaje hasta inicios del siglo XIX. Los trazos del parentesco, la memoria genealógica, el poder político, la territorialidad y la reproducción de los colectivos étnicos convergen en este avance de investigación que buscó trasuntar, a cuatro siglos de su prístina formulación, los afamados pasos de los Fernández Guarachi de Jesús de Machaca.

Agradecimientos: Una versión anterior de este trabajo fue presentada en el II Congreso Latinoamericano de Historia Indígena, realizado en San Salvador de Jujuy (Argentina) del 10 al 12 de octubre de 2018. Agradecemos las observaciones que Sonia Tell nos hiciera en aquella oportunidad, como así también las atentas lecturas de Ana María Presta y Juan Pablo Ferreiro y las sugerencias de los evaluadores de Autoctonía. Este trabajo fue realizado en el marco de los Proyectos PICT 20160481 y UBACyT F291, dirigidos por Ana María Presta, y FiloCyT 19-039, dirigido por el autor.

\section{Referencias citadas}

Abercrombie, T. A. (1998): “Tributes to bad conscience: charity, restitution, and inheritance in cacique and encomendero testaments of sixteenth-century Charcas”, en S. Kelloggy M. Restall, eds., Dead giveaways. Indigenous testaments of colonial Mesoamerica and the Andes, Salt Lake City, University of Utah Press, pp. 249-289.

Alaperrine-Bouyer, M. (2007): La educación de las elites indígenas en el Perú colonial, Lima, IFEA.

Arana Bustamante, L. (2017): “Hacia una perspectiva diacrónica y etnohistórica sobre parentesco andino, linealidad y ayllu", Intercambios. Estudios de Historia y Etnohistoria 2(2), pp. 28-40.

Arnold, D. Y. (2018): Los eventos del crepúsculo. Relatos 
históricos y hagiográficos de un ayllu andino en el tiempo de los españoles, La Paz, Plural-ILCA.

Assadourian, C. S. (1982): El sistema de la economía colonial. Mercado interno, regionesy espacio económico, Lima, IEP.

Astvaldsson, A. (2000): Las voces de los wak'a, La Paz, CIPCA.

Bauer, B. S. y C. Stanish (2001): Ritual and pilgrimage in the ancient Andes. The islands of the Sun and the Moon, Austin, University of Texas Press.

Bestard, J. (1998): Parentesco y modernidad, Barcelona, Paidós.

Boixadós, R. (1997): “Herencia, descendencia y patrimonio en La Rioja colonial”, Andes 8, pp. 199-224.

Boixadós, R. (2008): “Caciques y mandones de Malligasta. Autoridad y memoria en un pueblo de indios de La Rioja colonial”, Andes 19, pp. 251-278.

Bourdieu, P.(1991): El sentido práctico, Madrid, Taurus.

Burns, K. (2011): “Making indigenous archives: the quilcaycamayoc of colonial Cuzco", Hispanic American Historical Review 91(4), pp. 665-689.

Choque Canqui, R. (1993): Sociedad y economía colonial en el sur andino, La Paz, Hisbol.

Choque Canqui, R. (1998a): "Ayllus de la marka de Qaqayawiri” Estudios Bolivianos 6, pp. 7-73.

Choque Canqui, R. (1998b): "El parentesco entre los caciques de Pakasa”, en D. Y. Arnold, comp., Gente de carne y hueso. Las tramas del parentesco en los Andes, La Paz, CIASE-ILCA, tomo II, pp. 325-340.

Choque Canqui, R. (2003): Jesús de Machaqa: La marka rebelde. 1. Cinco siglos de historia, La Paz, Plural-CIPCA.

Clavero, B. (1994). Derecho indígena y cultura constitucional en América, México, Siglo XXI.

Conrad, G. W. y A. A. Demarest (1984): Religion and empire. The dynamics of Aztec and Inca expansionism. Cambrige, Cambridge University Press.

Cook, N. D. (1975): Tasa de la visita general de Francisco de Toledo, Lima, UNMSM.

Costilla, J. (2010): “El milagro en la construcción del culto a Nuestra Señora de Copacabana (virreinato del Perú, 1582-1651)", Estudios Atacameños 39, pp. 35-56.

de la Puente Luna, J. C. (2016): "En lengua de indios y en lengua española: cabildos de nuaturales y escritura alfabética en el Perú colonial”, en A. L. Izquierdo y de la Cueva, ed., Visiones del pasado. Reflexiones para escribir la historia de los pueblos indígenas de América, México, IIF-UNAM, pp. 51-113.

del Río, M. (2009): “De sacerdotes del Tawantinsuyu a cofrades coloniales: nuevas evidencias sobre los Acustopa y Viracocha Inga de Copacabana", Revista Andina 46, pp. 6-69.

Escobari de Querejazu, L. (2009): "Historia de la alfabetización en Bolivia. Época Colonial, s. XVI-XVIII”, Estudios Bolivianos 15, pp. 227-283.

Gisbert, T. (1980): Iconografía y mitos indígenas en el arte, La Paz, Gisbert. 
Gisbert, T. (1992): “Los curacas del Collao y la conformación de la cultura mestiza andina", en $\mathrm{H}$. Tomoeda y L. Millones, eds., 500 Años de mestizaje en los Andes, Senri Ethnological Studies 33, Osaka, National Museum of Ethnology, pp. 52-102.

Glave, L. M. (1989). Trajinantes. Caminos indígenas en la sociedad colonial. Siglos XVI / XVII, Lima, IAA.

Glave, L. M. (2013): "La petición grande de don Gabriel Fernández Guarache y el debate sobre la mita minera en un contexto de crisis colonial”, en R. Choque Canqui, ed., Mita, caciques y mitayos. Gabriel Fernández Guarache. Memoriales en defensa de los indios y debate sobre la mita de Potosí (1646-1663), Sucre, ABNB, pp. 177-211.

Herzog, T. (2007). “Nombres y apellidos: ¿cómo se llamaban las personas en Castilla e Hispanoamérica durante la época moderna?", Jahrbuch für Geschichte Lateinamerikas 44, pp. 1-35.

Jurado, M. C. (2014): “'Descendientes de los primeros’. Las probanzas de méritos y servicios y la genealogía cacical. Audiencia de Charcas, 1574-1719”, Revista de Indias LXXIV(261), pp. 387-422.

Levi, G. (1990): La herencia inmateiral. La historia de un exorcista piamontes del siglo XVII, Madrid, Nerea.

Manríquez S., V.y S. Sánchez (2003): “Memorias de la sangre, memorias de la tierra. Pertenencia, identidad y memoria entre los indígenas del Noroeste Argentino, Atacama y Chile central durante el Período Colonial", Estudios Atacameños 26, pp. 45-59.

Martínez Cereceda, J. L. (1995); Autoridades en los
Andes. Los atrubutos del señor, Lima, PCUP. Medinacelli, X. (2003): ¿Nombres o apellidos? El sistema nominativo aymara. Sacaca-S.XVII, La Paz-Lima, IEB-IFEA.

Morrone, A. J. (2010a): "Legitimidad, genealogía y memoria en los Andes meridionales: los Fernández Guarachi de Jesús de Machaca (Pacajes, siglos XVIXVII)", Memoria Americana. Cuadernos de Etnohistoria 18(2), pp. 211-237.

Morrone, A. J. (2010b): “Clero rural y liderazgo étnico en el corregimiento de Pacajes: la antigua iglesia de Jesús de Machaca (siglo XVII)", Anuario de Estudios Bolivianos, Archivísticos y Bibliográficos 16, pp. 445-475.

Morrone, A. J. (2013a): “Entre la vida y la muerte. Testamentos de don Gabriel y doña Lucrecia Fernández Guarachi (Jesús de Machaca, Pacajes, siglo XVII)", Corpus. Archivos virtuales de la alteridad americana 3(1). Disponible en web: http://ppct.caicyt.gov.ar/ index.php/corpus

Morrone, A. J. (2013b): "Estrategias estatales y liderazgo étnico en el corregimiento de Pacajes (1538-1620)", en A. M. Presta, ed., Aportes multidisciplinarios al estudio de los colectivos étnicos surandinos. Reflexiones sobre Qaraqara-Charka tres años después, La Paz, IFEA-Plural, pp. 343-372.

Morrone, A. J. (2014): “Reconfiguración de alianzas políticas en contextos críticos: los caciques de San Andrés de Machaca (Pacajes, Audiencia de Charcas, siglos XV-XVII)”, Boletín Americanista 68, pp. 187-210.

Morrone, A. J. (2015): “Memoria en la sangre y en la tierra. Liderazgo, sucesión y territorialidad en el 
sur andino (corregimiento de Pacajes, 1570-1650)", Indiana 32, pp. 205-234.

Morrone, A. J. (2016): "No todos los caciques fueron mallku. Mediación política truncada en los corregimientos de Pacajes y Omasuyos (Audiencia de Charcas, 1570-1630)”, Diálogo Andino 50, pp. 207-217.

Morrone, A. J. (2018): “Mujeres cacicales en el tablero colonial. Familia, parentesco y poder étnco en el lago Titicaca (1580-1750)", Andes 29(1), pp. 1-31.

Morrone, A. J. (2019): "Entre altares y escritorios. Liderazgo étnico y poder local en la pluma de tres curas-cronistas del lago Titicaca (1570-1650)", Memoria Americana. Cuadernos de Etnohistoria 27(1), pp.59-86.

Mumford, J. R. (2012): Vertical empire. The general resettlement of Indians in the colonial Andes, Durham-London, Duke University Press.

Noack, K. y K. Nowack (2017): “'Y otras menudençias de poco balor'. El testamento de Angelina Palla, Cajamarca, 1581", Meridional. Revista Chilena de Estudios Latinoamericanos 8, pp. 201-216.

Nowack, K. (2006): “'Como cristiano que soy': testamentos de la elite indígena en el Perú del siglo XVI", Indiana 26, pp. 51-77.

Nowack, K. (2013): "Measuring the passage of time in Inca and Early Spanish Peru", Indiana 30, pp. 77-98.

Pease G. Y., F. (1992): Curacas, reciprocidad yriqueza, Lima, PCUP.

Platt, T., T. Bouysse-Cassagne y O. Harris (2006):
Qaraqara-Charka. Mallku, inka y rey en la provincia de Charcas (siglos XV-XVII). Historia antropológica de una confederación aymara, Lima-La Paz, IFEA-Plural.

Presta, A. M. (2000): Encomienda, familia y negocios en Charcas colonial. Los encomenderos de La Plata, 15501600, Lima, IEP-BCRP.

Presta, A. M. (2002): “De testamentos, iniquidades de género, mentiras y privilegios: doña Isabel Sisa contra su marido, el cacique de Santiago de Curi”, en J. Flores Espinoza y R. Varón Gabai, eds., El hombre y los Andes. Homenaje a Franklin Pease G. Y., Lima, PCUP, tomo II, pp. 817-829.

Presta, A. M. (2009): “'Por el mucho amor que tengo'. Matrimonio indígena, poliginia y vida conyugal en Charcas, siglos XVI-XVII”, en M. Ghirardi, coord., Familias iberoamericanas ayer y hoy. Una mirada interdisciplinaria, Córdoba: ALAP, pp. 45-61.

Ramírez, S. E. (2005): To feed and be fed. The cosmological bases of authority and identity in the Andes, Stanford, Stanford University Press.

Ramírez, S. E. (2006): “Historia y memoria. La construcción de las tradiciones dinásticas andinas", Revista de Indias LXVI(236), pp. 13-56.

Ramos, G. (2010): Muerte y conversión en los Andes. Lima y Cuzco, 1532-1670, Lima, IEP-IFEA.

Ramos Gavilán, A. (2012 [1621]): Historia del célebre santuario de Nuestra Señora de Copacabana. Sucre: ABNB.

Remy Simatovic, M. del P. (2011): Los curacas de Caja- 
marca y el sistema colonial (Siglo XVI, inicios del XVII). Tesis de Maestría inédita, Lima, PCUP.

Rivera Cusicanqui, S. (1978). "El mallku y la sociedad colonial en el siglo XVII: el caso de Jesús de Machaca”, Avances 1, pp. 7-27.

Saignes, T. (1984). "Las etnias de Charcas frente al sistema colonial (Siglo XVII). Ausentismo y fugas en el debate sobre la mano de obra indígena, 1595-1665", Jahrbuch fur Geschichte Lateinamerikas XXI, pp. 27-75.

Saignes, T. (1985): Caciques, Tribute and Migration in the Southern Andes. Indian society and the 17th century colonial order (Audiencia de Charcas), Occasional Papers 14, Londres, ILAS-University of London.

Saignes, T. (1987a): "De la borrachera al retrato: los caciques andinos entre dos legitimidades (Charcas)". Revista Andina 9, pp. 130-170.

Saignes, T. (1987b): “Ayllus, mercado y coacción colonial: el reto de las migraciones internas en Charcas (siglo XVII)", en O. Harris, B. Larson y E. Tandeter, comps., La participación indígena en los mercados surandinos. Estrategias y reproducción social, siglos XVI-XX, La Paz, CERES, pp. 111-158.

Salles-Reese, V. (1997): From Viracocha to the virgin of Copacabana. Representations of the sacred at lake Titicaca, Austin, University of Texas Press.

Sanabria, H. (2001): "Exploring kinship in Anthropology and History: surnames and social tansformations in the Bolivian Andes", Latin American Research Review 36(2), pp. 137-155.
Sánchez-Albornoz, N. (1978): Indios y tributos en el Alto Perú, Lima, IEP.

Stern, S. J. (1986 [1982]): Los pueblos indígenas del Perú y el desafío de la conquista española. Huamanga hasta 1640, Madrid, Alianza.

Spalding, K. (1972): De indio a campesino. Cambios en la estructura social del Perú colonial, Lima, IEP.

Thomson, S. (2006): Cuando sólo reinasen los indios. La política aymara en la era de la insurgencia, La Paz, Muela del Diablo-Aruwiyiri.

Urioste de Aguirre, M. (1978): "Los caciques Guarache", Estudios Bolivianos en Homenaje a Gunnar Mendoza L., La Paz, pp. 131-140.

Wachtel, N. (2001): El regreso de los antepasados. Los indios urus de Bolivia, del siglo XX al XVI, México, FCE.

Zuloaga Rada, M. (2012): La conquista negociada: guarangas, autoridades locales e imperio en Huaylas, Perú (1532-1610), Lima, IEP-IFEA.

\section{Notas}

1Por su parte, el contingente obligado a la mita de Potosí fue de 122/123 varones adultos anuales durante el período 1585-1633 (Saignes, 1985).

2Biblioteca Central de la Universidad Mayor de San Andrés (BCUMSA, La Paz), Manuscrito 62, ff. 6r-8v. El expediente se encuentra incompleto: falta por lo menos un último folio donde debería constar la resolución del pleito. 
${ }^{3}$ Escapa a los objetivos de este trabajo reponer los debates que la teoría antropológica ha brindado sobre el concepto de "linaje" (cf. Arana Bustamante, 2017). En términos operativos, entendemos por "linaje" a los miembros de una familia cacical que, de manera consecutiva y durante al menos tres generaciones, ejercieron el gobierno de un pueblo de reducción, consolidando así su poder político. Así como "no todos los caciques fueron mallku" (Morrone, 2016), no todas las familias cacicales constituyeron un linaje.

${ }^{4}$ Archivo General de Indias (AGI, Sevilla), Audiencia de Lima 29, f. 61. Agradecemos a Felipe Ruan (Brock University, Canadá) el generoso y desinteresado envío de la versión digitalizada del documento.

${ }^{5}$ Abordaremos las edades de la población nativa consignadas en la documentación a modo de ejercicio analítico, atendiendo siempre a que las mismas (autoasumidas o sindicadas por informantes hispanocriollos) distaban de responder a cálculos cronológicos exactos y constituyen, por lo tanto, datos elusivos (Nowack, 2013).

6BCUMSA 62, f. 1r-2r.

7Si Axata Camaqui alegaba tener 78 años en 1576, para 1608 tendría 110 años, una edad exageradamente avanzada, aún para un importante cacique surandino.

8BCUMSA 191, f. 5v.

${ }^{9}$ BCUMSA 62, f. $8 v$.

10BCUMSA 62, f. 7r.

11BCUMSA 62, f. 6 r.
12Don Fernando Axata Camaqui podría haber tenido a sus tres hijos naturales y a algunas de sus diez hijas con las "seys mugeres viejas que me servian por criada" (BCUMSA 62, f. 7v), a cada una de las cuales otorgó cinco cargas de chuñu. El hijo menor, Felipe Guagua Pati, aparece registrado como "viejo y reservado" en la revisita de 1620, con 61 años, por lo cual habría nacido hacia 1559. Casado con Juana Callampa, de 50 años, tenían una hija llamada Ana Capa, de 20 años. Archivo General de la Nación (AGN, Buenos Aires), Sala XIII, Legajo 17-10-4, Revisita al pueblo de Jesús de Machaca (1620), f. 17r.

${ }^{13}$ Según consta en el amparo otorgado por el Licenciado Martín Pérez de Recalde, oidor de la Audiencia de La Plata, "de algunos dias a esta parte por fines vuestros os haveis querido esentaros de su subjecion, no le queriendo obedecer ni acudir con lo que sois obligados" (BCUMSA 48, ff. 3v-4v).

14Don Fernando Cayo Guarachi había actuado como alcalde y testigo en ocasión del servicio voluntario de 1576, cuando dijo tener alrededor de 27 años, por lo que habría nacido hacia 1549. Estimamos, pues, que para 1605 don Fernando debía tener alrededor de 56 años. Que su hijo don Pedro le haya adjudicado “mas de 70 años" abona a su intención de dar mayor fundamento a su petición.

15BCUMSA 48, ff. 6r-6v. AGN XIII 17-10-4. Revisita, f. 11r. Don Gabriel nació en 1603, siendo bautizado por el Licenciado Juan de Escobar el 4 de noviembre de ese año (AGI Escribanía 868A, primera pieza, f. 82r). Con respecto a don Diego, detectamos una incongruencia, ya que fue registrado en la revisita con ocho años de edad, pero resulta imposible que haya nacido hacia 1612 ya que su padre había muerto antes de esa fecha, 
como veremos más adelante.

${ }^{16}$ Archivo de La Paz (ALP), Registro de Escrituras (RE), Caja 9, Legajo 13, ff. 90r-90v: Andrés González de Vargas. Don García Martín había sido segunda persona del pueblo en 1600 (AGI Charcas 45, "Papeles de don Juan Baptista Quispe Sala capitan de los pacasas de urcosuyo", ff. 24r-25v).

17AGI Charcas 52, f. 800r; (Morrone, 2013b: 359-364)

18AGN XIII, 17-10-4. Revisita, f. 11r. La revisita arrojó un total de 588 tributarios sobre 2003 habitantes, lo que implicaba una caída del $26 \%$ de la subpoblación tributaria y de un $61,5 \%$ de la población total del pueblo con respecto a la visita toledana.

19Del cruce del auto de posesión con el padrón de revisita, identificamos las segundas personas del pueblo, don Martin Calli (ayllu Sullcatiti), don Francisco Layme (ayllu Colliri) y don Leandro Guarachi (ayllu Hilatiti, este último también tío paterno del cacique). Asimismo, individualizamos a los jilaqata (principales) de cada ayllu del pueblo: don Francisco Acapana (Chama), don Juan Cuti Guanca (Guaguatata), Martín Agnocuti (Achuma), don Agustín Pacsi Yucra (Chuma), García Mamani (Parina), Antonio Llusco (Conco), don Francisco Achu Yucra (Calla, futuro suegro del cacique), don Pedro Machaca (cacique de los uru del ayllu Ancoaqui), don García Acache (Yauriri) y don Cristóbal Vilca Callisaya (segunda persona de Titicana). BCUMSA 48, f. 10r.

20BCUMSA 48, ff. 9v-10r.

${ }^{21}$ AGN IX, 20-4-4, Pacajes 1623, f. 94r. El panorama demográfico de 1622 era peor aún que el de 1620. En solo dos años, la subpoblación tributaria había caído de 588 a 460, es decir, un 22\% (cifra que asciende al $42 \%$ en comparación con la visita toledana).

22AGN XIII, 17-10-4, f. 50r. Reconstruimos la filiación de doña María Hachama a través de los registros parroquiales resguardados en el Libro de Bautismos de Jesús de Machaca (LBJM), Iglesia de Jesucristo de los Santos de los Últimos Días (IJSUD), Microfilm 1278280 , Ítem 7, f. 138r (Morrone, 2010b: 462).

23BCUMSA 2216, f. 4v. Los "otros dos hijos" naturales, habidos en María Orcoma (natural del pueblo de San Pedro de Curaguara, BCUMSA 2216, f. 8v), posiblemente hayan sido María Guarachi, nacida en 1667 (AGN XIII, 18-1-2, Visita Jesús de Machaca, f. 16v) y Ana Guarachi, nacida el 5 de noviembre de 1672 (IJSUD, LBJM, f. 67r). Sus nombres no constan en el testamento porque quizás el cacique no las conociera. Por cierto, doña Lucrecia y doña María no fueron las únicas hijas legítimas del matrimonio (Choque Canqui, 2003: 90; Morrone, 2018: 11).

${ }^{24}$ AGN IX, 20-4-4, Visita Pacajes, f. 25r. Silvia Rivera Cusicanqui (1978: 15) identificó a don Diego Canqui como cacique de Caquingora, aunque en el documento (BCUMSA 2216, f. 16r) no consta su pueblo de origen. Proponemos que don Diego Canqui era el cacique de Calacoto casado con doña Lucrecia, toda vez que para esa época el cacique de Caquingora era don Pedro Alejo Sirpa Tico (ALP Juzgado Pacajes (PJJ), C4 [1671]; AGN XIII, 18-1-2 [1683]; ALP Expedientes Coloniales (EC) C31 E25 [1686]). El hecho de que don Diego figurara como difunto y doña Lucrecia como viuda (Archivo y Biblioteca Nacionales de Bolivia [ABNB], Expedientes Coloniales [EC] 1682-6, f. 17v; AGN XIII, 18-1-2, Visita Jesús de Machaca, f. 16r) corrobora esta hipótesis, que 
contradice la condición de "solterona" asignada a la hija del cacique (Choque Canqui, 2003: 60, 93).

${ }^{25} \mathrm{AGI}$ Escribanía 868A, primera pieza, ff. 176r-176v, 195r-195v, 462r. Suponemos que don Diego Canqui falleció entre 1661 (fecha de su último registro documental disponible) y 1669 (fecha en que su hermano don Vicente Canqui aparece como cacique de Calacoto, ver Glave, 2013: 207).

${ }^{26}$ ALP, Visita de Gerónimo Luis de Cabrera, Ambaná 1657 C2 D1, f. 2v. AGN IX, 20-4-4, Visita Pacajes, f. [82r] (Guaqui, 4r). Proponemos que fue Juana Guarachi quien casó con el cacique de Guaqui ya que su hermana doña Magdalena había tomado los hábitos (BCUMSA 2216, f. 19r).

${ }^{27} \mathrm{AGI}$ Escribanía 868A, primera pieza, ff. 423r y 473v-474r. El rumor fue desmentido meses después por el protector de naturales.

28BCUMSA 48, ff. 2r-3r. ALP PJJ, Caja 4. Para 1646, don Gabriel Fernández Guarachi contaba con once hijos. AGI Escribanía 868A, primera pieza, f. 206r.

${ }^{29}$ BCUMSA 2216, ff. 3r-3v, 5v-6r, 17r.

30 "Por lo visto se diferenció, dentro de la familia, entre los bienes propios adquiridos (incluso a nombre del común) y la transferencia del cargo político" (Choque Canqui, 2003: 105). ¿Un caso de herencia partida colonial (Conrad y Demarest, 1984: 91)?

31ALP PJJ Caja 1.

32BCUMSA 191, ff. 30r-30v.
33En julio de 1682, don Pedro presentó ante don Juan Francisco de Inda Vidaurre, corregidor de Pacajes, una provisión obtenida en enero de ese año, por la cual el virrey don Melchor de Navarra y Rocafull, duque de La Palata, ordenaba al corregidor redoblar los esfuerzos para reducir a la población nativa a sus respectivos pueblos, de modo que el cacique pudiera enterar la mita potosina (ALP PJJ C6). Su hijo, don Joseph Fernández Guarachi, diría años después "que recibi el cargo de governador de los yndios de este mesmo pueblo que fue por el año de 682 comensé a entender en la reduccion de los yndios ausentes y huidos y hacer padrones y listas de todos ellos para su mejor manejo y direccion". En efecto, el 2 de diciembre de 1682 realizaba el pago del tercio de San Juan (BCUMSA 191, ff. 8v, 33v). Sin embargo, el mismo documento señala que don Joseph había sido "llamado a esta sucesión por muerte de dicho su padre lo governó el dicho Maestre de Campo desde el año de 1681" (BCUMSA 191, f. 11r). Sugerimos que debe tratarse de un error de transcripción del amanuense que realizó el traslado.

34IJSUD, LBJM f. [38r].

${ }^{35}$ BCUMSA 48, ff. 38v-39r. Sobre la "cultura neoinca" cuzqueña de fines del siglo XVII y durante el siglo XVIII, ver Gisbert, 1980: 93-94 y Thomson, 2006: 37-39. Sobre los colegios para caciques en Cuzco y Charcas, ver Alaperrine-Bouyer, 2007 y Escobari de Querejazu, 2009.

36BCUMSA 48, ff. 16v-18r. Esta intromisión del corregidor acaso anticipara el rol que sus sucesores tendrían décadas más adelante en torno al reparto forzoso de mercancías (Choque Canqui, 2003: 236-239; Thomson, 2006: 97-100). 
37AGN XIII, 23-10-2. Diligencias actuadas por el corregidor de Potosí sobre la mita de su cerro (1690), ff. 33r-33v (Sánchez-Albornoz, 1978: 120-121).

38ALP PJJ C6. Habido en doña María Ardanza (ALP EC C53 E17, f. 2v), don Bonifacio Fernández Guarachi también fue capitán de mita en 1682 y en 1690 (Sánchez-Albornoz, 1978: 116-118; Choque Canqui, 2003: 100-102).

39BCUMSA 48, ff. 20v-22r.

${ }^{40}$ La longevidad de los caciques de Jesús de Machaca se explica, entre otros factores, por las mejores condiciones de vida que su posición socioeconómica les permitió alcanzar. Así, don Fernando Axata Camaqui habría muerto a los 85 años y su hijo don Fernando Cayo Guarachi antes de los 70. Don Gabriel Fernández Guarachi murió a los 69 años, mientras que don Joseph lo hizo a los 66. Los otros dos caciques, don Pedro Guarachi y su nieto don Pedro Fernández Guarachi, fallecieron a los 30-34 y a los 50 años, respectivamente, situaciones que generaron sendas "crisis sucesorias".

41Agradecemos esta orientación analítica a Ana María Presta y a Juan Pablo Ferreiro. De hecho, don Joseph Fernández Guarachi daría un paso más allá. En el memorial presentado en 1685 para probar su filiación y legitimidad, el cacique se presenta como "don Joseph Fernández Guarachi Ynga” (o Ynga Guarachi), sumando al apellido familiar el componente incaico heredado de su linaje materno, muy probablemente siguiendo las sugerencias de algún asesor letrado. BCUMSA 48, ff. 19r-20r. 